\title{
Comparative Determination of Levels of Volatile Organic Compounds (VOCs) at Some Selected Flow Stations in Delta State, Nigeria
}

\author{
Onwukeme Valentine Ifenna ${ }^{1}$, Etienajirhevwe Omonigho Frank ${ }^{2,}$ * \\ ${ }^{1}$ Deparment of Pure and Industrial Chemistry, Nnamdi Azikiwe University, Awka, Anambra State, Nigeria \\ ${ }^{2}$ Department of Science Laboratory Technology, Delta State Polytechnic, Otefe, Oghara, Nigeria \\ Email address: \\ omonigho4jesus@yahoo.com (E. O. Frank) \\ ${ }^{*}$ Corresponding author

\section{To cite this article:} \\ Onwukeme Valentine Ifenna, Etienajirhevwe Omonigho Frank. Comparative Determination of Levels of Volatile Organic Compounds \\ (VOCs) at Some Selected Flow Stations in Delta State, Nigeria. World Journal of Applied Chemistry. Vol. 5, No. 1, 2020 , pp. 6-12. \\ doi: 10.11648/j.wjac.20200501.12
}

Received: April 21, 2020; Accepted: May 11, 2020; Published: June 3, 2020

\begin{abstract}
Twelve air samples were collected from four sampling locations namely Transcorp Power Station, Warri Refinery and Petrochemical Company, Amukpe Flow Station and Platform Petroleum Company and were analyzed for the presence of volatile organic compounds (VOCs). Triplicate samplings were carried out within three months for fourteen days using the passive method. After collection, digestion and extraction, VOCs concentrations in each sample were determined with Gas Chromatography equipped with Mass Spectrophotometer (GC/MS). Mean results of analysis showed VOCs in the range of $1.21-60.30,9.12-30.80,5.38-66.94$ and $7.22-101.30 \mu \mathrm{g} / \mathrm{m}^{3}$ for Transcorp Power Station, Warri Refinery and Petrochemical Company, Amukpe Flow Station and Platform Petroleum Company respectively. Results obtained found all the study location to be contaminated with VOCs when compared with critical values for air quality guidelines. It was therefore recommended that as individuals, we should consider the consequences of our actions and work to improve the quality of air for future generation.
\end{abstract}

Keywords: Volatile Organic Compounds, Glass Tube, Concentration, Pollution, Contamination

\section{Introduction}

Pure air comprise of Oxygen (21\%) and Nitrogen (78\%) and a number of rare gases, of which Argon is the most plentiful. Carbon dioxide is present at a lower percentage concentration $(0.03 \%)$ than Argon (0.93\%); water vapour up to $4 \%$ by volume is also present. The Atmosphere also contain number of gases which at higher than usual concentration are harmful to human. This include Volatile Organic Compounds (VOCs) which are carcinogenic such as benzene and 1,3 - butadiene. They are potentially toxic and are referred to as air pollutants [1]. These pollutants are in the ambient air in gas phase and are sorbed to aerosols. The fate, transport and removal of organic compounds from the atmosphere by dry and wet deposition processes are strongly influenced by their gases - particle partitioning [2].

Concerns about the air we breathe have probably been around as long as mankind from the moment fire was invented; the pollution of the atmosphere became a problem [3]. Several effects of atmospheric volatile organic compounds (VOCs) are recognised such as their contribution to stratospheric ozone, ozone depletion, tropospheric photochemical effect, and enhancement of global greenhouse effects [4].

A considerable number of substances, carcinogenic or supposedly carcinogenic occur as outdoor and indoor air pollution of these carcinogenic substances, benzene, 1, 3 butadiene, etc, and the Poly Aromatic Hydrocarbons (PAHs) are the best known. Some of them are genotoxicarcinogous and as such any form of exposure no matter how small may in theory be associated with and increased risk of cancer [1]. The VOCs protocol under the convention on Long - Range Trans - Boundary Air Pollution (CLRTAP) defines VOCs as all organic compounds of an anthropogenic nature other than 
methane, that are capable of producing photochemical oxidants by reaction with Nitrogen oxides in the presence of sun light. VOC such as Benzene has half-life in the environment of less than one day and consequently does not disperse significant distance from its service and readily washed from the atmosphere by precipitation as well as can easily re - evaporate [5]. Other VOCs arising from the combination process of petroleum products dispersed relatively rapidly within the atmosphere. Motor vehicles are the principal source of such VOCs [6].

VOCs are known to be toxic to man due to greater exposure than $3200 \mathrm{mg} / \mathrm{m}^{3}$ that could result to neuro - toxic symptoms while persistent exposure to toxic level causes injury to bone marrow, resulting in consistent pancytopenia; Toluene causes dysfunctioning of the Central Nervous System (CNS); Acute experimental and repeated occupational exposure at levels greater than $375 \mathrm{mg} / \mathrm{m}^{3}$ has elicited dose related to CNS alteration such bas fatigue and confusion

The objective of this study is to quantitatively analyse VOCs associated with the atmosphere at some selected flow station in Delta State, Nigeria using GC/MS techniques; determine the level of significant difference across the studied locations; and determine the VOCs effects in the studied locations by comparing quantitative value with guideline provided by Occupation Safety for Health and Administration.

\section{Methods}

\subsection{Sample Collection}

Volatile Organic Compounds (VOCs) components were collected by the use of glass tubes opened at one end. The glass tube was packed with activated charcoal and was mounted on a pole at an average height of 2.0 meters from the ground [7]. The samplers were mounted and positioned in such a way to allow free flow of air through its opening for adsorption of VOCs components by the activated charcoal. This procedure was carried out at the four study locations and the mounted samplers were allowed to stay for a period of fourteen (14) days with regular monitoring. Triplicate samplings were carried out for three months.

\subsection{Harvesting of Samples}

All the samplers mounted were harvested after a period of fourteen (14) days. The samplers which were initially open for in-flow of air were then closed with special caps to avoid any form of contamination and desorption. The samplers were placed into tightly closed special bags and were kept in a refrigerator at a controlled temperature until they were processed. The glass fibre filters used for heavy metal component collection were placed in an air tightened container, water samples in a polypropylene containers and the soil in a black polythene bags. All the samples were handled with all carefulness to avoid contamination.

\subsection{Sample Extraction and Analysis}

Harvested samples for VOCs analysis were placed in vials in which they were weighed. $10 \mathrm{~mL}$ carbon disulphide $\left(\mathrm{CS}_{2}\right)$ was added as an extraction solvent and was reweighed [8]. Samples were then extracted using magnetic stirrer (Jennweary 1103) for thirty (30) minutes. The extracted samples were centrifuged for another thirty (30) minutes to obtain a clear phase at the top. $5 \mu \mathrm{L}$ of each of the extracted sample was injected into a Gas chromatography (GC) (Perkin Elmer Clarus 500) equipped with mass spectrophotometer. The GC/MS was standardized and calibrated; the GC with a capillary column ( $30 \mathrm{~m}$ by $25 \mu \mathrm{m}$ id, film thickness, $0.25 \mu \mathrm{m}$ ) was used and Helium was the carrier gas. After an initial holding time of five minutes, the oven temperature was increased from 45 to 120 degree centigrade $\left({ }^{\circ} \mathrm{C}\right)$ at a rate of $10^{\circ} \mathrm{C}$ per minute, and then to $150^{\circ} \mathrm{C}$ at $6^{\circ} \mathrm{C}$ per minute. The flow rate of the carrier gas was at a constant flow rate of $45 \mathrm{~mL} /$ minute. The bake time was 8 minutes at $260^{\circ} \mathrm{C}$. The split ratio was 1:40 and the injection and detection temperature were maintained at $250^{\circ} \mathrm{C}$ and $280^{\circ} \mathrm{C}$ respectively. The concentrations of the analytes were read from the chromatogram.

Table 1. Mean volatile organic compounds in air $\left(\mu \mathrm{g} / \mathrm{m}^{3}\right)$ in comparison with standard.

\begin{tabular}{|c|c|c|c|c|c|}
\hline Components & Transcorp Power & Warrirefinery & Amukpef/station & Platform petroleum & OSHA \\
\hline Acetone & 9.54 & 9.19 & ND & ND & 2400 \\
\hline Chloroform & 8.23 & 11.56 & ND & ND & 240 \\
\hline Benzene & 10.87 & 10.11 & ND & ND & N/A \\
\hline Bromomethane & 10.08 & 13.20 & 10.83 & 11.27 & N/A \\
\hline Toluene & 11.27 & 10.84 & 5.38 & 7.22 & 2 \\
\hline Trichloroethane & 23.40 & 11.93 & 9.89 & 10.14 & 45 \\
\hline 4-methyl-2-pentanone & 2.37 & 9.20 & 12.71 & 13.86 & 240 \\
\hline Ethylbenzene & 1.21 & 13.60 & 10.82 & 11.24 & 435 \\
\hline m-xylene & 12.13 & 16.30 & 15.24 & 16.77 & 435 \\
\hline p-xylene & 22.80 & 24.31 & 66.94 & 101.30 & 435 \\
\hline o-xylene & 2.52 & 9.12 & 11.25 & 12.52 & 435 \\
\hline Chlorobenzene & 22.40 & 5.52 & 11.03 & 13.22 & 350 \\
\hline Ethanol & 11.33 & 13.90 & 11.39 & 13.25 & 1900 \\
\hline
\end{tabular}




\begin{tabular}{llllll}
\hline Components & Transcorp Power & Warrirefinery & Amukpef/station & Platform petroleum & OSHA \\
\hline Carbon tetrachloride & 52.60 & 16.60 & 11.52 & 11.52 & N/A \\
Trichlorofluoro-methane & 20.40 & 5.57 & 11.38 & 11.41 & 5600 \\
Methylene chloride & 19.80 & 13.80 & 42.87 & 45.28 & 2 \\
Isopropyl acetate & 19.70 & 16.70 & 11.54 & 11.73 & 950 \\
Tetrahydrofuran & 23.10 & 25.30 & 11.56 & 11.59 & 590 \\
Naphthalene & 45.10 & 17.10 & 13.25 & 13.32 & 50 \\
n-Propylbenzene & 60.30 & 11.88 & 21.69 & 22.46 & N/A \\
1,2-Dichlorobenzene & 49.30 & 13.80 & 10.86 & 11.12 & 300 \\
n-Buthylbenzene & 22.50 & 13.70 & 10.25 & 10.33 & N/A \\
2,2-Dichlorobenzene & 3.96 & 23.60 & 10.29 & 11.39 & N/A \\
Tetrachloroethane & ND & 26.20 & 11.33 & 17.33 & 35 \\
Bromoform & ND & 30.80 & 15.26 & 12.05 & 5 \\
Isopropylbenzene & ND & 24.50 & & N/A \\
\hline
\end{tabular}

ND: Not detected; N/A: Not available

\section{Discussion}

Volatile organic compounds (VOCs) were found present in the four study locations with variations in their concentration. Among the VOCs, at Platform petroleum, and Amukpe flow station, Acetone, Chloroform and benzene were not detected. At platform petroleum, pxylene, methylene choride, n-propylbenzene, bromoform, 4-methyl-2-pentanone, naphthetene, ethanol and chloroform were in abundance with concentrations of $101.30,45.28,22.46,17.33,13.86,13.32,13.25$ and $13.22 \mu \mathrm{g} / \mathrm{m}^{3}$ respectively. At Transcorp power station, Naphthalene, 1,2-dichlorobenzene, trichlomethane, tetrahydrofuran (THF), Chlorobenzene, trichlorofluoromethane, and n-butylbenzene were in abundance with concentrations of $60.30,52.60,45.10$, $49.30,23.4023 .10,22.40,20.40$ and $22.50 \mu \mathrm{g} / \mathrm{m}^{3}$ respectively; At warri refinery, bromoform, Tetrahydrofuran (THF), tetrachloroethane, p-xylene, isopropylbenzene, 2,2-dichlorobenzene, isopropylacetate, carbon tetrachloride and $\mathrm{m}$-xylene were in abundance with concentratons of $30.80,25.30,26.20,24.31,24.50,23.60$, $16.70, \quad 16.60$ and $16.30 \mu \mathrm{g} / \mathrm{m}^{3}$ respectively while at Amukpe flow station, p-xylene, methylene chloride, n- propylbenzene, m-xylene and bromoform were in abundance with concentration of $66.94,42.87,21.69$, 15.24 and $15.26 \mu \mathrm{g} / \mathrm{m}^{3}$ respectively. There were significant difference between the study locations and the control sight and comparison of the various VOCs with air quality guidelines provided by occupational safety and health administration (OSHA) showed that toluene and methylene chloride polluted the environment while slight contamination was observed with other VOCs

Chloroform and trichloroethane effects on the human body highly depend on their dosage and the methods of administration. According to Wisconsons Department of Health Services, immediate or short after exposure to a level of $100 \mu \mathrm{g} / \mathrm{m}^{3}$ of chloroform and the trichloroethane in the atmosphere, one may feel tired and dizzy and have headache. The effects in humans increase proportionally always with its dosage. While in small amounts, they can make one feel lethargic and disoriented or unconscious and feel no pain sensation. In more severe dosage, it causes strained breathing, complete muscle relaxation and paralysis of the chest muscles [9]. Figures 1 and 2 below showed levels of chloroform and trichloroethane in the selected flow stations compared with OSHA Standard.

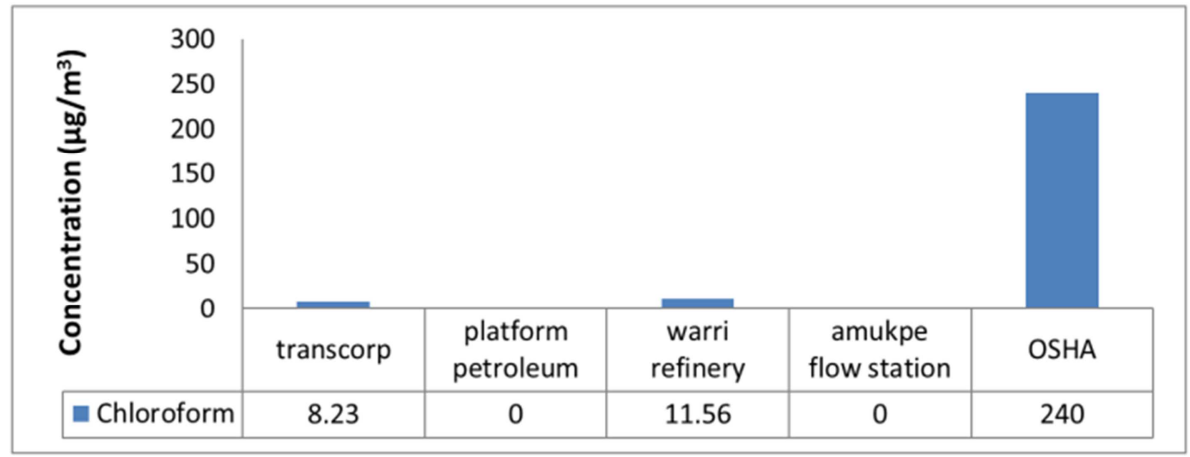

Figure 1. Chloroform in air compared with OSHA. 


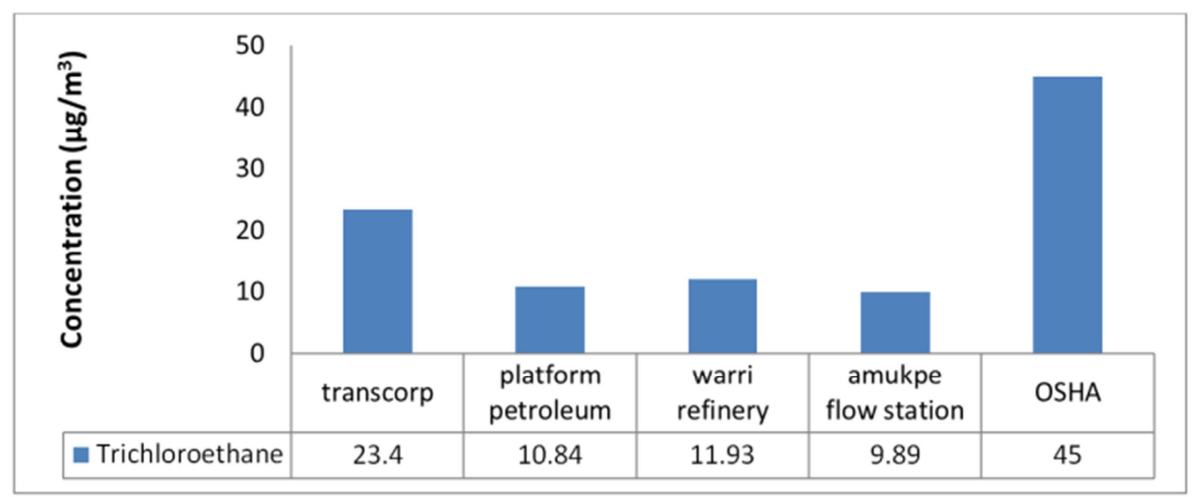

Figure 2. Trichloroethane in air compared with OSHA.

Tetrachloroethane was found to be within permissible value set out by OSHA but it is worth mentioning that its main effects are the liver and neurology. Acute (short-term) inhalation exposure to very high levels of it has resulted in effects on the liver and respiratory, central nervous, and gastrointestinal systems in humans. Chronic (long-term) inhalation exposure in humans results in jaundice and an enlarged liver, headaches, tremors, dizziness, numbness, and drowsiness.

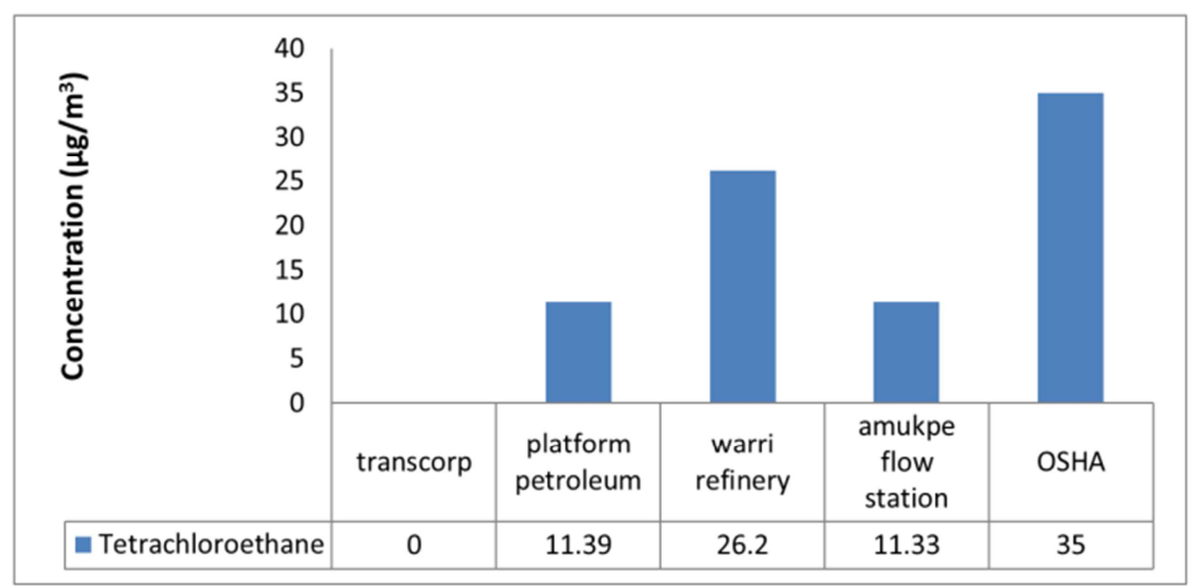

Figure 3. Tetrachloroethane in air compared with OSHA.

The presence of bromoform in the study locations were found to be the permissible value set by OSHA except for the control site at which it was not detected. Bromoform exposure may occur through the emission from gas flaring stations and also from the consumption of chlorinated drinking water. Acute (short-term) effects from inhalation or ingestion of high levels of bromoform in humans and animals consist of nervous system effects such as the slowing down of brain functions, and injury to the liver and kidney. Chronic (long-term) animal studies indicate effects on the liver, kidney, and central nervous system (CNS) from oral exposure to bromoform. Human data are considered inadequate in providing evidence of cancer by exposure to bromoform, while animal data indicate that long-term oral exposure can cause liver and intestinal tumors. Bromoform has been classified as human carcinogen

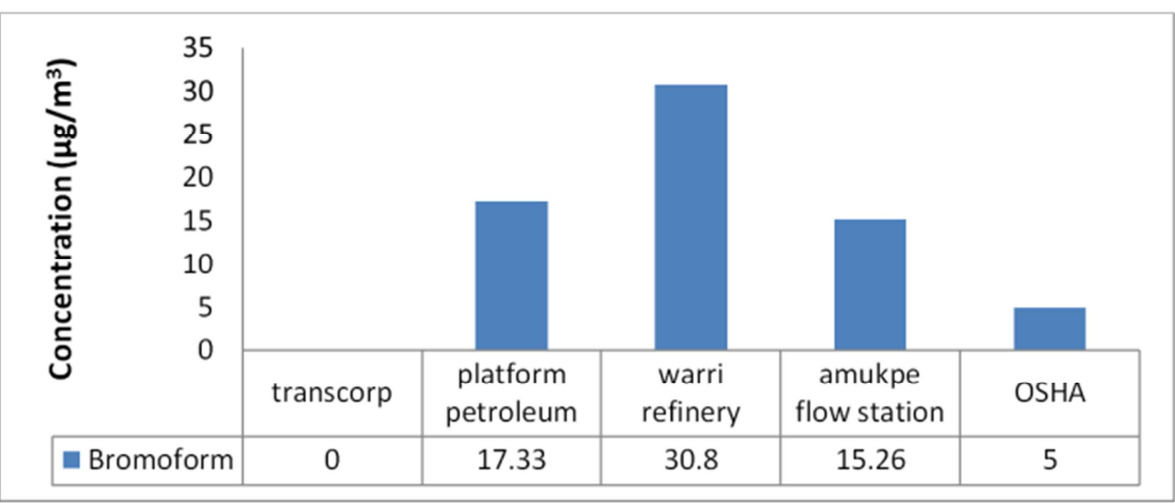

Figure 4. Bromoform in air compared with OSHA. 
The presence of methylene chloride at all the study locations including the control site were found to pollute the environment as values obtained were above the maximum permissible value of $2 \mu \mathrm{g} / \mathrm{m}^{3}$ of OSHA. It is worth mention that when the limit is exceeded and one is exposed to such concentration, irritation of the nose and throat and affects the central nervous system would surfaced. Methylene chloride is a possible mutagen and is reasonably anticipated to be a human carcinogen. OSHA considers methylene chloride to be a potential occupational carcinogen. Short-term exposures to high concentrations may cause mental confusion, light headedness, nausea, vomiting, and headache. Continued exposure may also cause eye and respiratory tract irritation. Exposure to methylene chloride may make symptoms of angina more severe. Skin exposure to liquid methylene chloride may cause irritation or chemical burns. The figure below showed the comparison between the study sites and OSHA standard.

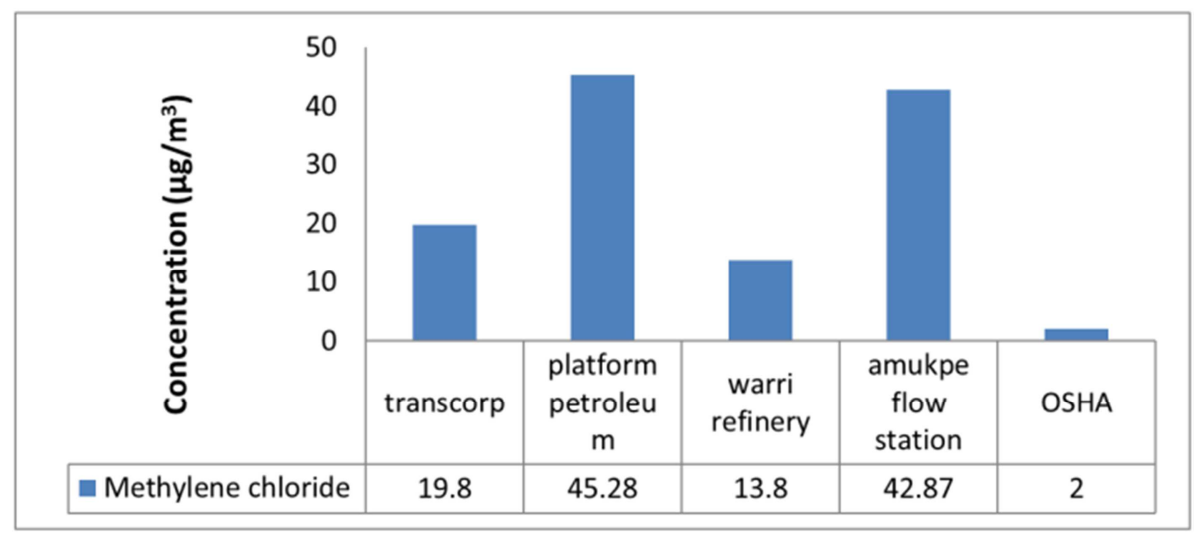

Figure 5. Methylene chloride in air compared with OSHA.

The three isomers of xylene (that is $o-, m$ - and $p$-xylene) were found to be within the permissible value of OSHA but it should be noted that the effect of inhaling xylene vapor or being exposed to it, leads to depression of the central nervous system, with symptoms such as headache, dizziness, nausea and vomiting. The effects can begin to occur with exposure to air levels of about $100 \mu \mathrm{g} / \mathrm{m}^{3}$. They are reversible and become more noticeable and serious as the length of time of exposure increases. Irritation of the nose and throat can occur at approximately $200 \mu \mathrm{g} / \mathrm{m}^{3}$ after 3 - 5 minutes. Accidental splash in the eye may damage the surface of the eye, which will heal within a few days. Exposure to xylene at levels of $200 \mu \mathrm{g} / \mathrm{m}^{3}$ or greater can irritate the lungs, causing chest pain and shortness of breath. Extreme overexposure can result in pulmonary edema. However, there is no evidence that repeated, low-level exposure has any long-term effects on the lung. At very high levels of exposure, xylene can injure the liver and kidneys, but this is extremely unlikely to happen without noticeable effects on the nervous system. Symptoms of nausea, vomiting and gastric discomfort were observed in workers exposed to xylene vapors which were reversible. Workers exposed to xylenes $\left(14 \mu \mathrm{g} / \mathrm{m}^{3}\right)$ has been reported reduced grasping power and reduced muscle power in the extremities more frequently than the unexposed controls. This is due to the neurological effect rather than a direct effect on the muscles [10]. Xylene, like other organic solvents, can dissolve the skin's natural protective oils. Frequent or prolonged skin contact can cause irritation and dermatitis, dryness and cracking of the skin. Damaged skin may allow greater absorption of chemicals. Xylene easily penetrates most ordinary clothing and can become trapped in ordinary gloves and boots. Xylene trapped in the clothing can cause burns and blistering [11].
The presence of trichlofluoromethane was found to be within the permissible values of OSHA but it should be noted that when the set limit of trichlofluoromethane is exceeded and when one is exposed to it over a long period of time, health effects may occur such as irritation of the skin and eyes; Contact with the liquid can cause frostbite, lightheaded and dizzy, irregular heartbeat, which can be fatal. These can occur without other warning symptoms [12].

The exposure of 1,2-dichlorobenzene and chlorobenzene to human skin for 15 minutes resulted in a burning sensation and the development of erythema and blistering within 24 hours. Subsequent hyper pigmentation of the affected area developed and can persist for number of months. Exposure to 1,2-dichlorobenzene and chlorobenzene vapours at $100 \mu / \mathrm{m}^{3}$ has been reported to cause some respiratory irritation in humans [13]. Eye and upper respiratory tract irritation has been reported by laboratory workers following exposures estimated to be no greater than $100 \mu / \mathrm{m}^{3}$ for 8 hours [14].

All the study locations were in safe condition with ethylbenzene but it should be known that when one is exposed to ethylbenzene, many factors will determine whether the substance would be harmful. These factors include the dose (how much), the duration (how long), and how you come in contact with it. It should be consider that any other chemicals one is exposed to and the age, sex, diet, family traits, lifestyle, and state of health are very important factor that can be used to determine the effect that could result from being exposed to it. Exposure to air contaminated with ethylbenzene at high levels for short periods can cause eye and throat irritation while exposure to higher levels above the recommended limit can result in vertigo and dizziness [9]. Acute exposure to ethylbenzene in the atmosphere causes respiratory effects, such as throat irritation 
and chest constriction, irritation of the eyes, and neurological, respiratory effects, such as throat irritation and chest constriction, irritation of the eyes, and neurological effects such as dizziness, have been noted from acute inhalation exposure to ethylbenzene in humans [15]. Chronic exposure to ethylbenzene by inhalation in humans has shown conflicting results regarding its effects on the blood. In one study of workers occupationally exposed to ethylbenzene, effects on the blood were noted, while in another study, no adverse effects on the blood were seen [12].

The concentration of naphthalene at all the locations were higher than the maximum permissible value of OSHA including the control site and it is worthy to mention that naphthalene above the recommended value by inhalation, ingestion and dermal contact is associated with hemolyticanemia, damage to the liver, and, in infants, neurological damage. Symptoms of such exposure include headache, nausea, vomiting, diarrhea, malaise, confusion, anemia, jaundice, convulsions, and coma. Cataracts have been reported in humans acutely exposed to naphthalene by inhalation and ingestion [16]. Chronic exposure of workers to naphthalene has been reported to cause cataracts and retinal hemorrhage. Chronic inflammation of the lung, chronic nasal inflammation, hyperplasia of the respiratory epithelium in the nose, and metaplasia of the olfactory epithelium were reported in mice chronically exposed to naphthalene through inhalation [15].

The presences of toluene in the study locations including the control site were found to be higher than the OSHA permissible value for ambient air. Emissions to the atmosphere result from point sources and area source. An extensive database on human exposure to toluene indicates that dysfunction of the CNS is of primary concern. Deficits in neurobehavioural functioning have been viewed as precursors of more serious indications of CNS toxicity. Toluene above its permissible value typically involves cognitive dysfunction. Evidence of abnormal brainstem auditory evoked potential is considered to be an early indicator of CNS injury.

The concentration of acetone from the study locations were within the OSHA permissible values of $2400 \mu \mathrm{g} / \mathrm{m}^{3}$. However, when one is exposed to acetone or inhaled its vapour, it goes into the blood which then carries it to all the organs in your body. If it is a small amount, the liver breaks it down to chemicals that are not harmful and uses these chemicals to make energy for normal body functions. Breathing moderateto-high levels of acetone for short periods of time, however, can cause nose, throat, lung, and eye irritation; headaches; light-headedness; confusion; increased pulse rate; effects on blood; nausea; vomiting; unconsciousness and possibly coma; and shortening of the menstrual cycle in women. Swallowing very high levels of acetone can result in unconsciousness and damage to the skin in the mouth. Skin contact can result in irritation and damage to your skin. The smell and respiratory irritation or burning eyes that occur from moderate levels are excellent warning signs that can help in avoiding breathing damaging levels of acetone [15].

4-methyl-2-pentanone concentration in air of the study locations was within the permissible value of OSHA of $240 \mu \mathrm{g} / \mathrm{m}^{3}$ which showed that the environment is in safe condition as regard 4-methyl-2-pentanone. However, a harmful contamination of the air can be reached rather quickly on evaporation of this substance when the set limit is exceeded. Short term exposure of 4-methyl-2-pentanone vapour is known to irritate the eyes, the skin and the respiratory tract. Swallowing the liquid may cause aspiration into the lungs with the risk of chemical pneumonitis. The substance may cause effects on the central nervous system at high concentrations, resulting in narcosis while repeated or prolonged contact with skin may cause dermatitis

Isopropyl acetate was in conformity with limit of OSHA for ambient air. However, it is worth noting this substance is an irritant of the eyes and mucous membranes which may cause central nervous system depression at very high concentrations [17]. Exposure to $400 \mu \mathrm{g} / \mathrm{m}^{3}$ of it for 3 to 5 minutes results in mild irritation of the eyes, nose, and throat; at $800 \mu \mathrm{g} / \mathrm{m}^{3}$, these symptoms intensify. A postmortem examination in a case of massive ingestion revealed extensive hemorrhagic tracheabronchitis, bronchopneumonia, and hemorrhagic pulmonary edema and prolonged skin contact with isopropyl acetate causes eczema and sensitivity [17].

The figure below therefore showed the concentrations of VOCs among the four locations studied

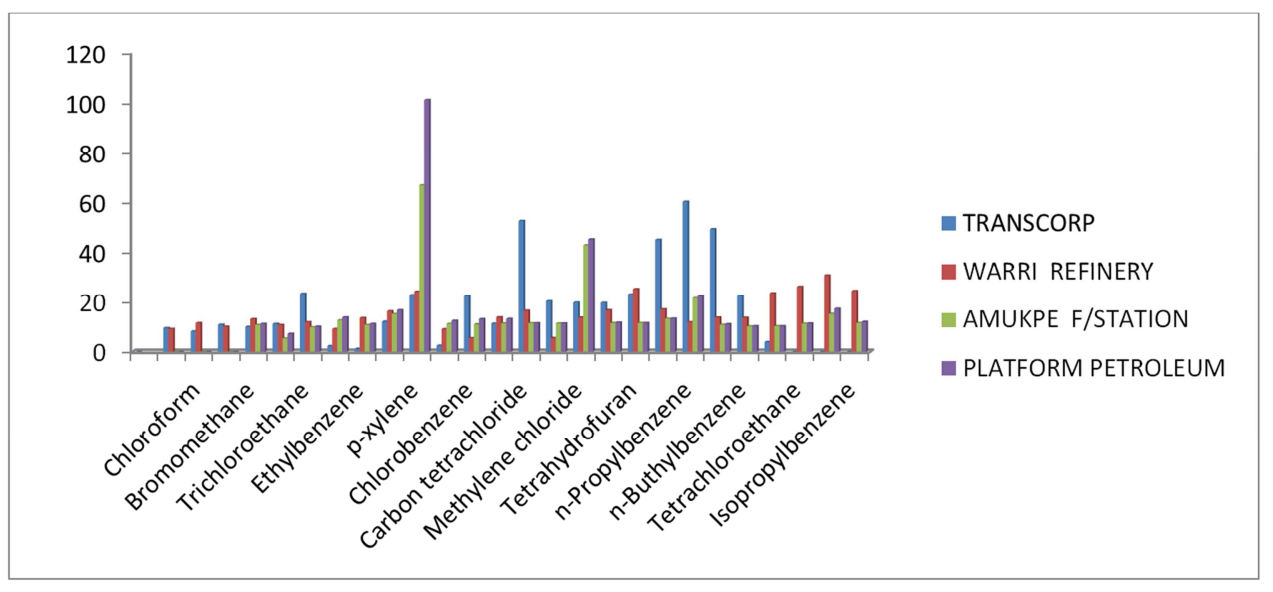

Figure 6. Concentrations of VOCs among the four locations. 


\section{Conclusion and Recommendation}

All the studied locations are found to be contaminated with volatile organic compounds (VOCs). Analytical results found some areas polluted while others contaminated or slightly polluted based on comparison of results of analysis with critical values (limits) set by Occupational Safety and Health Administration (OSHA). Breathing is obligatory and without it there is no life. It is today's generations of people who have realized that the air they breathe is not an unlimited natural resources. It should be a concern to effectively manage air for a sustainable future. The management of air should enquire methods and techniques based on sound science and careful application towards finding solution to already polluted air

There should be future development of air pollution management by bringing awareness to the general public of the scale of air pollution and how to manage it. There should be the development of philosophy and attitude towards monitoring air pollution. As an individual we must consider the consequences for our actions and work to improve air quality for future generation. The management of air pollution problems cannot be over emphasized hence we must avoid the reoccurrence of air pollution problem we are facing today

\section{Acknowledgements}

Staff of Delta State Polytechnic, Otefe, Oghara, Nigeria and $\mathrm{Mr}$ BangboyeAdeola of Lighthouse Petroleum Engineering Company, GRA, Effurun, Delta State, Nigeria are appreciated for the use of their laboratory facilities for chemical analysis.

\section{References}

[1] Harrop, D. O. Air Quality Assessment and Management, A Practical Guide, Spon Press, USA and Canada, 2002, p. 278.

[2] Bidleman, T. F. Anthropogenic processes: Wet and dry deposition of organic compounds are controlled by their vapour particle partitioning, Environmental Science and Technology Journal vol. 22, 1988, pp 361-367.

[3] Dewulf, J; Langenhove, H. V. Atmospheric volatile organic compounds in ambient air and Natural Waters: A review on recent development of analytical methodology, performance and interpretation of field measurement, Journal of Chromatography A 843, 2000, pp 143-177.
[4] Brimblecombe, P. The Big Smoke, A history of air pollution in London since medieval times, Routledge, London, 1987.

[5] Scottish Office. An Assessment of Air Quality Monitoring in Scotland Central Research Unit, Scottland, 1998 p. 174.

[6] Department of the Environment. The United Kingdom National Air Quality Strategy, HMSO, London, 1997, p. 188.

[7] Department of the Environment, Transport and the Regions. Review and Assessment: Monitoring air Quality, LAQM. HMSO, London, 2000, p. 247.

[8] American Standard for Testing and Materials (ASTM). Method D: 3687-07: Standard practice for sampling atmospheric air to collect organic compound vapour (activated charcoal tube adsorption method) Annual book of ASTM standard, Vol. 11, 2015, pp. 184-189.

[9] Agency for Toxic Substances and Disease Registry (ATSDR). Toxicological profile for ethylbenzene. Public Health Service, U.S. Department of Health and Human Services, Atlanta, 2010 .

[10] Uchida Y., Nakatsuka H., Ukai H., Watanabe T., Liu Y. T and Huang M. Y. Symptoms and signs in workers exposed predominantly to xylene. International Archive of Occupation and Environment and Health. Vol. 64, 1993, pp. 597-605.

[11] Department of Health. Qualification of the Effect of Air Pollution on Health in the United Kingdom, HMSO, London, 1998, p. 128.

[12] Agency for Toxic Substances and Disease Registry (ATSDR) Toxicological Profile for ethylbenzene. Public Health Service, U.S. Department of Health and Human Services, Atlanta. 1999.

[13] Elkins, H. B. The chemistry of industrial toxicology. $2^{\text {nd }}$ edition. New York, John Wiley and Sons Inc., 1959, p. 298.

[14] Zapata-Gayon, C., Zapata-Gayon, N. and Gonzalez-Angulo, A. Clastogenic chromosomal aberrations in 26 individuals accidentally exposed to Ortho-dichlorobenzene vapors in the National Medical Center in Mexico City. Architectural Journal of Environment and Health, vol. 37, 1982, pp 231-235.

[15] Agency for Toxic Substances and Disease Registry (ATSDR). Toxicological Profile for Naphthalene. Public Health Service, U.S. Department of Health and Human Services, Atlanta, 1995.

[16] United State Environmental Protection Agency (USEPA). Toxicological Review of Naphthalene in Support of Summary Information on the Integrated Risk Information System (IRIS). National Center for Environmental Assessment, Cincinnati, 1998.

[17] Hathaway, G. J., Proctor, N. H., Hughes, J. P and Fischman, M. L Proctor and Hughes' chemical hazards of the workplace. 3rd edition. New York, NY: Van Nostrand Reinhold, 1991. 